Pacific Journal of Mathematics

THE EXTREMAL STRUCTURE OF LOCALLY COMPACT 


\section{THE EXTREMAL STRUCTURE OF LOCALLY COMPACT CONVEX SETS}

\section{J. C. Hankins and R. M. Rakestraw}

Let $X$ be a locally compact closed convex subset of a locally convex Hausdorff topological linear space $E$. Then every exposed point of $X$ is strongly exposed. The definitions of denting (strongly extreme) ray and strongly exposed ray are given for convex subsets of $E$. If $X$ does not contain a line, then every extreme ray is strongly extreme and every exposed ray is strongly exposed. An example is given to show that the hypothesis that $X$ be locally compact is necessary in both cases.

By a locally convex space we mean a real Hausdorff locally convex topological linear space $E$. $E^{*}$ will denote the topological dual of $E$. The set of extreme points of $X$ will be denoted by ext $X$. The closed line segment between the points $x$ and $y$ in $E$ will be denoted $[x, y]$. The following definition was given by M. Rieffel $[6, p .75]$ for subsets of a Banach space. I. Namioka also studied these points in [4].

Definition 1. If $X$ is a subset of a locally convex space, then $x \in X$ is called a denting (strongly extreme) point of $X$ if for any nbhd $U$ of $x, x \notin$ cl-conv $(X \backslash U)$. The set of all denting points of $X$ will be denoted by dent $X$.

Clearly, every denting point is an extreme point. It follows from the separation theorem for convex sets that $x_{0}$ is a denting point of $X$ iff for each nbhd $U$ of $x_{0}$ there exist $f \in E^{*}$ and $\alpha \in R$ such that $x_{0} \in\{x: f(x)<\alpha\} \cap X \subseteq X \cap U$. An example is given in [6, p. 75] to show that not every extreme point is a denting point. However, this is not the case in a locally compact set. For completeness we state the following theorem due to J. Reif and V. Zizler [5, p. 64].

THEOREM 1. Assume $X$ is a locally compact closed convex set in a locally convex space $E$. Then any extreme point of $X$ is a strongly extreme point of $X$ with respect to the relative topology from $E$.

A point $p$ of a set $X$ in a locally convex space $E$ is an exposed point of $X$ if there exists an $f \in E^{*}$ such that $f(x)>f(p)$ for each $x \in X \backslash\{p\}$. The following definition was given by J. Lindenstrauss [3, p. 140] for subsets of a Banach space. 
Definition 2. A point $x \in X$, where $X \subseteq E$, is called a strongly exposed point of $X$ whenever (i) there exists an $f \in E^{*}$ such that $f(y)>f(x)$ for each $y \in X \backslash\{x\}$, and (ii) for any net $\left\{x_{\alpha}\right\} \subseteq X, f\left(x_{\alpha}\right) \rightarrow f(x)$ in $R$ implies that $x_{\alpha} \rightarrow x$ in $E$. The set of all strongly exposed points of $X$ is denoted by strexp $X$.

It is easy to see from the definition that every strongly exposed point is an exposed point. J. Lindenstrauss in [3, p. 145] gave an example of a set which has an exposed point that is not strongly exposed. However, this is not the case if the set is locally compact.

THEOREM 2. Let $X$ be a locally compact closed convex subset of a locally convex space $E$, then every exposed point of $X$ is a strongly exposed point of $X$.

Proof. Let $U$ be a closed convex nbhd of $x$ such that $U \cap X$ is compact and assume $f \in E^{*}$ such that $f(x)<f(y)$, for all $y \in X \backslash\{x\}$. Since $x$ is an exposed point of $X, x$ is an extreme point of $X$. By Theorem 1, $x$ is a denting point of $X$. Thus, there exist $g \in E^{*}$ and $\alpha \in R$ such that $\{x: g(x)<\alpha\} \cap X \subseteq$ (int $U) \cap X$.

If $\{x: g(x) \geqq \alpha\} \cap(X \cap U)=\varnothing$, then it follows immediately that $U \cap X \subseteq\{x: g(x)<\alpha\} \cap X \subseteq$ (int $U) \cap X$. Therefore $U \cap X$ is a nonempty open and closed set in the connected set $X$. Hence, $U \cap X=$ $X$ which implies $X$ is compact. Let $\left\{x_{\alpha}\right\}$ be a net in $X$ such that $f\left(x_{\alpha}\right) \rightarrow f(x)$ in $R$. Since $X$ is compact, there is a subnet $\left\{x_{\beta}\right\}$ of $\left\{x_{\alpha}\right\}$ and a vector $y \in X$ such that $x_{\beta} \rightarrow y$. Thus, $f\left(x_{\beta}\right) \rightarrow f(y)=f(x)$ in $R$ and so $y=x$. For any subnet $\left\{x_{\gamma}\right\} \subseteq\left\{x_{\alpha}\right\}$ there is similarly a subnet which converges to $x$, which proves that $x_{\alpha} \rightarrow x$ in $E$.

On the other hand, if $W=\{x: g(x) \geqq \alpha\} \cap(X \cap U) \neq \varnothing$, then $W$ is a nonempty compact convex subset of $X$ which does not contain $x$. Hence, there is a $w \in W$ such that $f(x)<f(w)=\inf f(W)$. Let $y \in X \backslash U$, then $[x, y] \subseteq X$. $U$ is a closed convex nbhd of $x$; hence, there exists a $z \in$ Bdry $U$ such that $z \in[x, y]$. Since $z \in \operatorname{Bdry} U$, then $z \notin$ int $U$ and $z \notin\{x: g(x)<\alpha\}$. Therefore, $z \in\{x: g(x) \geqq \alpha\} \cap(X \cap U)$ so $f(z) \geqq$ $f(w)$. But $y-x=\lambda(z-x)$ where $\lambda>1$. Hence, $f(y-x)=\lambda f(z-x)>$ $f(z-x)$ which implies $f(y)>f(z) \geqq f(w)$. Let $\left\{y_{\alpha}\right\}$ be a net in $X$ such that $f\left(y_{\alpha}\right) \rightarrow f(x)$ in $R$. Since $\left\{y_{\alpha}\right\} \subseteq X$ and $f(y) \geqq f(w)>f(x)$ for each $y \in X \backslash U$, we may assume that $\left\{y, y_{a}\right\} \subseteq U \cap X$. Since $U \cap X$ is compact, it follows from the previous argument that $y_{\alpha} \rightarrow x$ in $E$.

As V. Klee has shown in [1] and [2], it is possible to extend the Krein-Milman theorem to certain noncompact convex sets with the aid of the notion of extreme ray. An extreme ray of a closed convex set $X$ 
is a closed half-line $\rho \subseteq X$ such that whenever $x, y \in X$ and $\lambda x+$ $(1-\lambda) y \in \rho$ for some $\lambda$ with $0<\lambda<1, x, y \in \rho$.

Definition 3. A ray $\rho=\{x+\lambda z: \lambda \geqq 0, z \neq 0\}$ of a convex set $X$ in a topological linear space $E$ is a denting (strongly extreme) ray of $X$ if for any nbhd $U$ of $0, \rho^{\prime} \cap \operatorname{cl}-\operatorname{conv}\left[X^{\prime} \backslash(x+\langle z\rangle+U)\right]=\varnothing$, where $X^{\prime}$ is any bounded convex subset of $X, \rho^{\prime}=\rho \cap X^{\prime}$ and $\langle z\rangle$ denotes the onedimensional linear subspace generated by $z$. Denote the union of all denting rays of $X$ by rdent $X$.

It is easy to show that every denting ray of a convex set $X$ is an extreme ray of $X$. The following theorem and example show that extreme rays and denting rays coincide in some instances and are distinct in others.

THEOREM 3. Let $X$ be a locally compact closed convex subset of a locally convex space $E$, then every extreme ray of $X$ is a denting ray of $X$.

Proof. Let $\rho$ be an extreme ray of $X$. We may assume without loss of generality that $\rho=\left\{\lambda x_{0}: \lambda \geqq 0\right\}, x_{0} \neq 0$. Let $X^{\prime}$ be a bounded convex subset of $X$ and let $f_{0}$ be in $E^{*}$ such that $f_{0}$ is positive on $K \backslash\{0\}$, where $K$ is the union of all rays in $X$ which emanate from 0 , and $X \cap\left\{x: f_{0}(x) \leqq t\right\}$ is compact, for each $t \in R$. Such a functional exists by Theorem 3.2 in [1]. Since $X^{\prime}$ is bounded and convex, $\operatorname{cl}\left(X^{\prime}\right)$ is bounded and convex. According to a result of Klee $\left[1\right.$, p. 236], $\mathrm{cl}\left(X^{\prime}\right)$ is compact which implies sup $f_{0}\left(\operatorname{cl}\left(X^{\prime}\right)\right)<\infty$. Then we may assume $X^{\prime} \subseteq\left\{x: f_{0}(x) \leqq 1\right\} \cap X=X^{\prime \prime}$. Let $W=\left\{x: f_{0}(x)=1\right\} \cap X$ and assume $f_{0}\left(x_{0}\right)=1$. Then $x_{0} \in \operatorname{ext}(W)$ and $W$ is compact, since $X^{\prime \prime}$ is compact. By Theorem $1, x_{0}$ is a denting point of $W$. Let $U$ be a nbhd of zero and let $g \in E^{*}$ and $\alpha>0$ such that $x_{0} \in\{x: g(x)<\alpha\} \cap W \subseteq\left(x_{0}+U\right) \cap W$. Let $T=\{x: g(x)=\alpha\} \cap W$. Then $T$ is compact, convex and $T \cap\left\langle x_{0}\right\rangle=\varnothing$. Let $f \in E^{*}$ and $\beta>0$ such that $f\left(\left\langle x_{0}\right\rangle\right)<\beta<\inf f(T)$. Since $0 \in\left\langle x_{0}\right\rangle$, we have $0=f\left(\left\langle x_{0}\right\rangle\right)<\beta<$ $\inf f(T)$.

If $y \in W$ such that $f(y)<\beta$, then $f_{0}(y)=1$ and $\left[x_{0}, y\right] \cap T=\varnothing$, since $f\left(x_{0}\right)<\beta$. It follows that $g(y)<\alpha$ and hence, $y \in\left(x_{0}+U\right) \cap W \subseteq$ $\left\langle x_{0}\right\rangle+U$.

On the other hand, if $y \in X$ such that $f_{0}(y)<1$ and $f(y)<\beta$, then there is a unique $\lambda>0$ such that $f_{0}\left(y+\lambda x_{0}\right)=1$. Again from Klee [1, p. 235] we have $y+\lambda x_{0} \in X$. Hence, $y+\lambda x_{0} \in W$ and $f\left(y+\lambda x_{0}\right)=$ $f(y)<\beta$. By the previous argument, it follows that $y+\lambda x_{0} \in x_{0}+U$ and so $y \in(1-\lambda) x_{0}+U \subseteq\left\langle x_{0}\right\rangle+U$.

In both cases we have $y \in\{x: f(x)<\beta\} \cap X^{\prime \prime}$ implies $y \in\left\langle x_{0}\right\rangle+U$. Hence, $X^{\prime \prime} \backslash\left(\left\langle x_{0}\right\rangle+U\right) \subseteq X^{\prime \prime} \backslash\{x: f(x)<\beta\} \subseteq\{x: f(x) \geqq \beta\}$. Thus, $\quad \operatorname{cl}-\operatorname{conv}\left[X^{\prime} \backslash\left(\left\langle x_{0}\right\rangle+U\right)\right] \subseteq\{x: f(x) \geqq \beta\}$. Now $f\left(\rho^{\prime}\right)<\beta$, since 
$f\left(\left\langle x_{0}\right\rangle\right)<\beta$ and $\rho^{\prime}=\left(X^{\prime} \cap \rho\right)$, so $\rho^{\prime} \cap$ cl-conv $\left[X^{\prime} \backslash\left(\left\langle x_{0}\right\rangle+U\right)\right]=\varnothing$. Therefore, $\rho$ is. a denting ray of $X$.

EXAmple 1. Let the space be $\ell_{2}$ with the canonical basis $\left\{e_{n}\right\}$, and $X=\operatorname{cl}-\operatorname{conv}\left(\left\{e_{n} ; n=2,3, \cdots\right\}\right)$. Then $0 \in X$ and $e_{1}$ is in $\ell_{2} \mid X$. Let $C$ be the cone generated by $X$ with vertex $e_{1}$, then $C$ is a closed convex subset of $\ell_{2}$. Let $\rho$ be the ray of the cone through 0 . Clearly, $\rho$ is an extreme ray of $C$. Let $S_{\frac{1}{2}}(0)$ be the open ball of radius $1 / 2$ centered on 0 . Clearly, $e_{n} \notin S_{\frac{1}{2}}(0)$ so $e_{n} \notin\left\langle e_{1}\right\rangle+S_{\frac{1}{2}}(0)$ and it follows that $e_{n} \in$ cl-conv $\left[X \backslash\left(\left\langle e_{1}\right\rangle+S_{\frac{1}{2}}(0)\right)\right]$ for $n \geqq 2$. However, $\left\{e_{n}\right\}$ converges weakly to 0 and cl-conv $\left[X \backslash\left(\left\langle e_{1}\right\rangle+S_{\frac{1}{2}}(0)\right)\right]$ is weakly closed so $0 \in$ cl-conv $\left[X \backslash\left(\left\langle e_{1}\right\rangle+S_{\frac{1}{2}}(0)\right)\right]$. Hence $\rho$ is not a denting ray of $C$.

A ray $\rho$ in $X$, where $X \subseteq E$, is an exposed ray of $X$ if there exist $f \in E^{*}$ and $\alpha \in R$ such that $\rho=\{x: f(x)=\alpha\} \cap X$ and $f(X \backslash \rho)>\alpha$. The next definition was given by V. Zizler in [7, p. 55] for subsets of a Banach space.

Definition 4. Let $X$ be a convex set in a locally convex space $E$ and $\rho$ a closed ray in $X$. Then $\rho$ is a strongly exposed ray of $X$ if (i) there exist $f \in E^{*}$ and $r \in R$ such that $f(x)=r$ for $x \in \rho$ and $f(x)>r$ for $x \in X \backslash \rho$, and (ii) $\left\{x_{\alpha}\right\}$ is eventually in $\rho+U$, whenever $U$ is a nbhd of 0 and $\left\{x_{\alpha}\right\}$ is a bounded net in $X$ such that $f\left(x_{\alpha}\right) \rightarrow r$. The set of all strongly exposed rays will be denoted by $\operatorname{rstrexp} X$.

Clearly every strongly exposed ray is an exposed ray. The following proposition, theorem, and examples show the relationships among denting ray, exposed ray and strongly exposed ray.

Proposition 1. Let $\rho$ be a strongly exposed ray of a convex set $X$ in a locally convex space $E$. Then $\rho$ is a denting ray of $X$.

Proof. We may assume $\rho=\left\{\lambda x_{0}: \lambda \geqq 0\right\}, x_{0} \neq 0$. Let $f \in E^{*}$ such that $\rho=\{x: f(x)=0\} \cap X$ and $f(x)>0$ for each $x \in X \backslash \rho$. Let $U$ be a nbhd of zero and $X^{\prime}$ a bounded convex subset of $X$. Assume for each positive integer $n$ there is an $x_{n} \in\{x: f(x)<(1 / n)\} \cap X^{\prime}$ such that $x_{n} \notin\left\langle x_{0}\right\rangle+U$. Clearly $\left\{x_{n}\right\}$ iş bounded and $f\left(x_{n}\right) \rightarrow 0$. Hence, there exists a positive integer $N$ such that $x_{n} \in \rho+U$ for $n \geqq N$. This is a contradiction; so there is a positive integer $N^{\prime}$ such that $\left\{x: f(x)<\left(1 / N^{\prime}\right)\right\} \cap X^{\prime} \subseteq$ $\left(\left\langle x_{0}\right\rangle+U\right) \cap X^{\prime}$. Thus, cl-conv $\left[X^{\prime} \backslash\left(\left\langle x_{0}\right\rangle+U\right)\right] \subseteq\left\{x: f(x) \geqq\left(1 / N^{\prime}\right)\right\}$ which implies $\left(\rho \cap X^{\prime}\right) \cap \operatorname{cl}-\operatorname{conv}\left[X^{\prime} \backslash\left(\left\langle x_{0}\right\rangle+U\right)\right]=\varnothing$; so $\rho$ is a denting ray of $X$.

THEOREM 4. Let $X$ be a locally compact closed convex subset of a locally convex space $E$, then every exposed ray of $X$ is a strongly exposed ray of $X$. 
Proof. Let $\rho$ be an exposed ray of $X$. We may assume that $\rho$ emanates from the origin. Let $f \in E^{*}$ such that $\rho=X \cap\{x: f(x)=0\}$ and $f(x)>0$ for $x \in X \backslash \rho$. Let $\left\{x_{\alpha}\right\}$ be a bounded net in $X$ such that $f\left(x_{\alpha}\right) \rightarrow 0$ in $R$ and let $U$ be a nbhd of 0 . There exists a nbhd $V$ of 0 such that $V$ is closed, balanced and convex, $V \subseteq U$ and $V \cap X$ is compact. Let $\left\{x_{\beta}\right\}$ denote the set of all vectors in the net $\left\{x_{\alpha}\right\}$ which lie in $X \backslash U$. If $\left\{x_{\beta}\right\}$ is not a subnet of $\left\{x_{\alpha}\right\}$, then $\left\{x_{\alpha}\right\}$ is eventually in $U=0+U \subseteq \rho+U$ and the conclusion follows.

If $\left\{x_{\beta}\right\}$ is a subnet of $\left\{x_{\alpha}\right\}$, then it suffices to show that $\left\{x_{\beta}\right\}$ is eventually in $\rho+U$. By Theorem 1,0 is a denting point of $X$, since 0 is an extreme point of $X$. Let $g \in E^{*}$ and $a>0$ such that $\{x: g(x)<a\}$ $\cap X \subseteq V \cap X$. Since $x_{\beta} \notin V$, then $g\left(x_{\beta}\right) \geqq a$, for each $\beta$. The net $\left\{x_{\alpha}\right\}$ is bounded, so there exists a number $b>0$ such that $g\left(x_{\beta}\right) \leqq b$, for each $\beta$. Hence, $0<a \leqq g\left(x_{\beta}\right) \leqq b$, for each $\beta$. If $y_{\beta}=\left[a / g\left(x_{\beta}\right)\right] x_{\beta}$, then $y_{\beta} \in\{x: g(x)=a\} \cap X$. Since $\{x: g(x)<a\} \cap X \subseteq V \cap X$ and $V \cap X$ is compact, then $\{x: g(x)=a\} \cap X$ is compact; so there is a subnet $\left\{y_{\gamma}\right\} \subseteq\left\{y_{\beta}\right\}$ and a point $y \in\{x: g(x)=a\} \cap X$ such that $y_{\gamma} \rightarrow y$ in $E$. Since $g\left(x_{\beta}\right)$ is bounded and $f\left(x_{\beta}\right) \rightarrow 0$ in $R$, we have $y \in\{x: f(x)=0\}$ $\cap X$ and thus, $y \in \rho$. Hence, $y \in\{x: g(x)=a\} \cap \rho$. It follows immediately that $\{y\}=\{x: g(x)=a\} \cap \rho$. Let $W=\{x: g(x)=a\} \cap X$ and $z \in W \backslash\{y\}$. Then $z \in W \backslash \rho$ which implies $f(z)>0$. Thus, $y$ is exposed by $f$ on $W$. Since $f\left(y_{\beta}\right) \rightarrow 0=f(y)$, by Theorem 2 we have $y_{\beta} \rightarrow y$ in $E$. Hence, there is a $\lambda_{0}$ such that $y_{\beta} \in y+(a / b) V$, for $\beta \geqq \lambda_{0}$. If $z_{\beta}=\left[g\left(x_{\beta}\right) / a\right] y$, then $z_{\beta} \in \rho$, for each $\beta$. But $y_{\beta}=\left[a / g\left(x_{\beta}\right)\right] x_{\beta}$, so $x_{\beta} \in\left[g\left(x_{\beta}\right) / a\right] y+\left[g\left(x_{\beta}\right) / a\right](a / b) V \subseteq \rho+V \subseteq \rho+U$, for all $\beta \geqq \lambda_{0}$. Therefore, the net $\left\{x_{\beta}\right\}$ is eventually in $\rho+U$ and it follows that $\rho$ is a strongly exposed ray of $X$.

ExAmple 2. The ray $\rho$ defined in Example 1 is exposed by $f=\left(0, \frac{1}{2}, \frac{1}{3}, \cdots, 1 / n, \cdots\right)$ on $C$. Therefore $\rho$ is an exposed ray of $C$ that is not a denting ray of $C$ so by Proposition $1 \rho$ is not a strongly exposed ray of $C$.

EXAmple 3. Let the space be $R^{3}$ and

$$
X=\operatorname{conv}\left[\left\{(x, y, z): x^{2}+y^{2} \leqq 1,-1 \leqq y \leqq 0 \text { and } z=1\right\} \cup(1,1,1)\right]
$$

Let $C$ be the cone generated by $X$ with vertex $(0,0,0)$. Then $C$ is a closed convex subset of $R^{3}$. Let $\rho$ be the ray of the cone through the point $(1,0,1)$. It is easy to see $\rho$ is not an exposed ray of $C$, but $\rho$ is a denting ray of $C$.

From the preceding work we can restate two of Klee's theorems ([2, Th. 2.3, p. 91], [1, Th. 3.4, p. 237]) as follows: 
THEOREM 5. Suppose $X$ is a locally compact closed convex subset of a normed linear space, and $X$ contains no line. Then ext $X \subseteq$ $\mathrm{cl}(\operatorname{strexp} X)$ and $X=\mathrm{cl}-\operatorname{conv}(\operatorname{strexp} X \cup \operatorname{rstrexp} X)$.

THEOREM 6. If $X$ is a locally compact closed convex subset of a locally convex space, and $X$ contains no line, then $X=$ cl-conv(dent $X \cup \operatorname{rdent} U)$.

\section{REFERENCES}

1. V. Klee, Extremal structure of convex sets, Archiv. Math., 8 (1957), 234-240.

2. - Extremal structure of convex sets II, Math. Z., 69 (1958), 90-104.

3. J. Lindenstrauss, On operators which attain their norm, Israel J. Math., 1 (1963-64), 139-148.

4. I. Namioka, Neighborhoods of extreme points, Israel J. Math., 5 (1967), 145-152.

5. J. Reif and V. Zizler, On strongly extreme points, Comment. Math. Prace Mat., 18 (1974/75), 63-70.

6. M. A. Rieffel, Dentable subsets of Banach spaces, with application to a Radon-Nikodym theorem, in Proc. Conf. Functional Analysis U. C. Irvine, Thompson, Washington, D.C. 1967.

7. V. Zizler, On extremal structure of weakly locally compact convex sets in Banach spaces, Comment Math. Univ. Carolinae 13, 1 (1972), 53-61.

Received August 4, 1975 and in revised form November 3, 1975.

UNIVERSITY OF MISSOURI - ROLLA 


\section{PACIFIC JOURNAL OF MATHEMATICS}

\section{EDITORS}

RICHARD ARENS (Managing Editor)

University of California

Los Angeles, California 90024

\author{
R. A. Beaumont \\ University of Washington \\ Seattle, Washington 98105
}

\section{J. DugunduI}

Department of Mathematics University of Southern California Los Angeles, California 90007

D. Gilbarg and J. Milgram

Stanford University

Stanford, California 94305

\section{ASSOCIATE EDITORS}

E. F. BECKENBACH
B. H. NeumanN

F. Wolp
K. YoshidA

\section{SUPPORTING INSTITUTIONS}

UNIVERSITY OF BRITISH COLUMBIA

CALIFORNIA INSTITUTE OF TECHNOLOGY

UNIVERSITY OF CALIFORNIA

MONTANA STATE UNIVERSITY

UNIVERSITY OF NEVADA

NEW MEXICO STATE UNIVERSITY

OREGON STATE UNIVERSITY

UNIVERSITY OF OREGON

OSAKA UNIVERSITY

\author{
UNIVERSITY OF SOUTHERN CALIFORNIA \\ STANFORD UNIVERSITY \\ UNIVERSITY OF HAWAII \\ UNIVERSITY OF TOKYO \\ UNIVERSITY OF UTAH \\ WASHINGTON STATE UNIVERSITY \\ UNIVERSITY OF WASHINGTON \\ AMERICAN MATHEMATICAL SOCIETY
}

The Supporting Institutions listed above contribute to the cost of publication of this Journal, but they are not owners or publishers and have no responsibility for its contents or policies.

Mathematical papers intended for publication in the Pacific Journal of Mathematics should be in typed form or offset-reproduced (not dittoed). double spaced with large margins. Underline Greek letters in red, German in green, and script in blue. The first paragraph or two must be capable of being used separately as a synopsis of the entire paper. Items of the biblography should not be cited there unless absolutely necessary, in which case they must be identified by author and Journal, rather than by item number. Manuscripts, in duplicate, may be sent to any one of the four editors. Please classify according to the scheme of Math. Reviews, Index to Vol. 39. All other communications should be addressed to the managing editor, or Elaine Barth, University of California, Los Angeles, California, 90024.

100 reprints are provided free for each article, only if page charges have been substantially paid. Additional copies may be obtained at cost in multiples of 50 .

The Pacific Journal of Mathematics is issued monthly as of January 1966. Regular subscription rate: $\$ 72.00$ a year (6 Vols., 12 issues). Special rate: $\$ 36.00$ a year to individual members of supporting institutions.

Subscriptions, orders for back numbers, and changes of address should be sent to Pacific Journal of Mathematics, 103 Highland Boulevard, Berkeley, California, 94708.

PUBLISHED BY PACIFIC JOURNAL OF MATHEMATICS, A NON-PROFIT CORPORATION Printed at Jerusalem Academic Press, POB 2390, Jerusalem, Israel.

Copyright (C) 1976 Pacific Journal of Mathematics All Rights Reserved 


\section{Pacific Journal of Mathematics}

\section{Vol. 64, No. $2 \quad$ June, 1976}

Richard Fairbanks Arnold and A. P. Morse, Plus and times............. 297

Edwin Ogilvie Buchman and F. A. Valentine, External visibility ......... 333

R. A. Czerwinski, Bonded quadratic division algebras.............. 341

William Richard Emerson, Averaging strongly subadditive set functions in unimodular amenable groups. II .........................

Lynn Harry Erbe, Existence of oscillatory solutions and asymptotic behavior for a class of third order linear differential equations ............. 369

Kenneth R. Goodearl, Power-cancellation of groups and modules........ 387

J. C. Hankins and Roy Martin Rakestraw, The extremal structure of locally compact convex sets ...................................

Burrell Washington Helton, The solution of a Stieltjes-Volterra integral

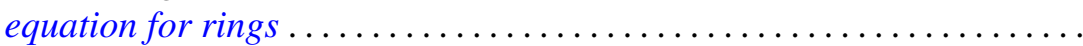

Frank Kwang-Ming Hwang and Shen Lin, Construction of 2-balanced

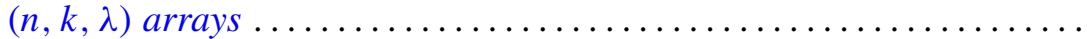

Wei-Eihn Kuan, Some results on normality of a graded ring ... 455

Dieter Landers and Lothar Rogge, Relations between convergence of series and convergence of sequences ......................... 465

Lawrence Louis Larmore and Robert David Rigdon, Enumerating immersions and embeddings of projective spaces ................

Douglas C. McMahon, On the role of an abelian phase group in relativized problems in topological dynamics..................

Robert Wilmer Miller, Finitely generated projective modules and TTF classes...

Yashaswini Deval Mittal, A class of isotropic covariance functions ...

Anthony G. Mucci, Another martingale convergence theorem ...

Joan Kathryn Plastiras, Quasitriangular operator algebras ...

John Robert Quine, Jr., The geometry of $p\left(S^{1}\right) \ldots \ldots \ldots$. 